\title{
Migraciones por amor: diversidad y complejidad de las migraciones de mujeres
}

\author{
Jordi Roca i Girona \\ Montserrrat Soronellas Masdeu \\ Yolanda Bodoque Puerta \\ Universitat Rovira i Virgili. Departament d'Antropologia, Filosofia i Treball Social \\ jordi.roca@urv.cat; mariamontserrat.soronellas@urv.cat; yolanda.bodoque@urv.cat
}

\section{Resumen}

El artículo analiza un tipo de migración, que hemos denominado por amor, que aparece de manera emergente a partir de la década de los años 90 en el marco de la irrupción del nuevo orden mundial caracterizado por el creciente protagonismo de las TIC. La exploración de los proyectos migratorios de las mujeres que han migrado por amor, nos sitúa ante la complejidad y la diversidad de las situaciones migratorias, puesto que plantean abiertamente la existencia de motivaciones para migrar que trascienden el modelo que atribuye a las migraciones una causalidad económica. El amor, la formación de una familia en destino o la emancipación son, entre otros, algunos de los motivos aducidos por las mujeres cuando explican su migración.

El trabajo de campo, consistente en la realización de más de 70 entrevistas en profundidad a parejas mixtas formadas por hombres españoles y mujeres eslavas o latinoamericanas, nos ha mostrado que los proyectos migratorios de las mujeres migrantes por amor reflejan algunas singularidades que son exploradas en el artículo. El carácter individualizado de la migración; la baja intensidad de las relaciones transnacionales que mantienen las mujeres migrantes; la ausencia de un proyecto de retorno; y un proceso de incorporación a la sociedad de llegada que, a pesar de ser más cómodo, puede acabar consolidando una situación de dependencia de las mujeres respecto a sus parejas.

Palabras clave: migraciones internacionales; migraciones femeninas; género; familia; matrimonios mixtos.

\section{Abstract. Migrations for love: Diversity and complexity in women's migrations}

This paper focuses on a specific kind of migration we call migration for love, which arose in the 1990s as a result of the emergence of the new world order characterized by the increasing role of ICTs. Exploring the migration projects of women who have migrated out of love reveals the complexity and diversity of migratory situations given that it uncovers the existence of motivations for migration that go beyond the model of economic causality 
attributed to migration. Love, the desire to raise a family on arrival, and emancipation are among the reasons given by women when explaining their decision to migrate.

The field work, which mainly comprised more than 70 interviews of couples in a mixed marriage of Spanish men to Slavic or Latin American women has shown that the migration projects of women who migrate for love exhibit particular features which are explored in the article. The individualized nature of migration, the low intensity of transnational relations maintained by the migrant women, the absence of a project to return, and the process of integration of these women into the host society, in spite of being more convenient, lead them to eventually consolidate a situation of dependency on their partners.

Keywords: international migrations; female migrations; gender; family; mixed marriages.

\begin{aligned} & \multicolumn{2}{c}{ Sumario } \\ & El amor como motivo $\begin{array}{l}\text { Proyecto individual y de familia en } \\ \text { destino: replantear la reagrupación }\end{array} \\ &$ Amor y papeles: esposas y migrantes $\begin{array}{l}\text { En síntesis. Una migración negada } \\ \text { y dependiente }\end{array} \\ &$ Irse sin mirar atrás Referencias bibliográficas \end{aligned}

En poco más de diez años - los que van de la primera mitad de la década de 1970 a la segunda mitad de la década de 1980—, España pasó de ser un país de emigración a ser uno de inmigración. Si bien el papel de las mujeres en los flujos migratorios en la primera de las dos fases señaladas fue generalmente invisibilizado y/o se le otorgó un carácter secundario, no ha ocurrido lo mismo cuando se ha abordado el estudio en la segunda fase, en la que el rol de las mujeres inmigrantes ha adquirido un protagonismo relevante (véanse los trabajos pioneros para España de Gregorio, 1998, y de Oso, 1998) vinculado principalmente a la división internacional del trabajo.

La literatura clásica sobre migraciones, en efecto, se fundamentó, por lo general, en la asunción incuestionable de la causalidad económica de las mismas, así como del carácter individual y del protagonismo masculino que las animaba (véase, por ejemplo, Harris y Todaro, 1970; Rothenberg, 1977; Zolberg, 1983). La consideración del nuevo orden global en relación con los procesos migratorios, no obstante, contribuye a delimitar nuevas geografías y tipologías en relación con la migración — migraciones de crisis, de mujeres independientes, de profesionales y trabajadores cualificados, de estudiantes, de jubilados, medioambientales, etc. (King, 2002)—, entre las cuales se encuentran las que nosotros hemos denominado «migraciones por amor». Nuestra aportación aborda un fenómeno, el de las llamadas «mail order brides» (Halualani, 1995; Ordóñez, 1997; Robinson, 1996; Scholes, 1999; Simmons, 1999), esposas de alquiler, temporales, por correspondencia, etc., muy alejado, por una parte, de las realidades de otros colectivos de mujeres migrantes que han sido 
ampliamente estudiadas desde la perspectiva del género (Hondagneu-Sotelo, 1997; Gregorio, 1998; Oso, 1998 y 2007; Agustín, 2003) y, por otra parte, a menudo diluido bajo las etiquetas más o menos (im)pertinentes del turismo o del mercado sexual internacional (véase, entre otros, Truong, 1990; Pettman, 1997; Clift y Carter, 2000; Bauer y McKercher, 2003; Brennan, 2004; Piscitelli, 2004; Bessa y Sacramento, 2006). Nuestra aproximación toma en cuenta también el marco de la transnational migration theory (véanse, entre otros, Brycesson y Vuorela, 2002; Portes, 2005; Levitt y Glick-Schiller, 2004; Parella, 2007; Pedone, 2008; Suárez, 2008), en la medida en que aborda el análisis de un tipo de migración que se fragua en el espacio transnacional, durante la etapa de noviazgo, y que, no obstante, caracterizamos por la baja intensidad de las prácticas transnacionales de las parejas una vez constituidas en destino.

Nuestro trabajo ${ }^{1}$, pues, quiere poner de relieve un tipo de migración escasamente considerada ${ }^{2}$, así como la particularidad de la misma. Se trata, además, de un tipo de migración principalmente femenina, entre cuyas características destacan, por un lado, la importancia de las motivaciones de género como desencadenantes del proceso y, por otro lado, la incorporación diferenciada que estas migrantes por amor realizan en la sociedad de acogida. Estas migraciones nos hablan de mujeres que emprenden la aventura migratoria como un proceso individual con la finalidad de formar una familia o una pareja en destino. La recepción de estas mujeres en España será distinta a la que recibirían si hubieran efectuado otro tipo de migración, de ahí que se vean afectadas sus redes personales y también la forma en que se verán a ellas mismas y serán vistas en destino con relación a otros colectivos de inmigrados.

Si bien este tipo de migración no constituye una realidad muy relevante en términos estadísticos, sí que representa un núcleo significativo, por cuanto

1. Proyecto 766-47-05 (2006-2008) del Instituto de la Mujer: Amor importado, migrantes por amor: La constitución de parejas entre españoles y mujeres de América Latina y de Europa del Este en el marco de la transformación actual del sistema de género en España (Jordi Roca i Girona (dir.), Yolanda Bodoque Puerta, Marija Djurjevich, Lidia Martínez Flores y Montserrat Soronellas Masdeu). La investigación ha incorporado una perspectiva cualitativa, tanto de obtención como de análisis de los datos, con un total de 65 entrevistas guiadas en profundidad, 59 de carácter individual (con un miembro de la pareja o con los dos pero separadamente) y 6 de carácter doble (a parejas), lo que representa el contacto con un total de 71 personas entrevistadas, fundamentalmente hombres españoles -19 en total-y mujeres eslavas (ucranianas y rusas principalmente -17 entre ambas-) y latinoamericanas ( 15 en total, cerca de la mitad brasileñas), por ser éstas las principales regiones y nacionaliades de procedencia de las mujeres casadas binacionalmente con hombres españoles (véase Roca et al., 2008). También se entrevistó a diversos responsables de agencias matrimoniales y a otras personas relacionadas con el tema (un abogado experto en ley de extranjería, la directora de una revista dirigida a la comunidad eslava, etc.). La selección de informantes se llevó a cabo siguiendo la técnica de la bola de nieve, es decir, recurriendo inicialmente a un pequeño número de personas (amigos, parientes, conocidos, personal de las agencias, consulados, asociaciones, etc.) para, a partir de aquí, ir ampliando la red de informantes mediante la colaboración de estas personas del grupo inicial.

2. E incluso, como hemos podido comprobar, directamente negada por amplios sectores sociales y académicos. 
supone la toma activa de decisiones de naturaleza algo distinta a las presentes en la mayor parte del colectivo migrante. Nos referimos, en primer lugar, a la participación conjunta en este proceso de toma de decisiones de la mujer - migrante - en origen y de la pareja en destino, $y$, también, a la puesta en funcionamiento de un marco de gestión distinto en lo relativo a las diferencias culturales, ya que la «esposa» o pareja se desmarca del proceso de migración tradicional basado en redes de apoyo. Tanto es así que, en este tipo de migraciones, la incorporación cultural y social de las mujeres migrantes en la sociedad de acogida es directa y supone una inmersión más intensa e inmediata, con el consiguiente impacto en sus redes sociales, tanto en origen como en destino.

En efecto, en 1996, el primer año en que tenemos datos estadísticos sobre matrimonios mixtos, se realizaron en España apenas 8.000 matrimonios binacionales, esto es: uniones heterosexuales entre un cónyuge español y otro extranjero. Algo más de una década después, en 2009, esta cifra se había elevado a casi 30.000. De estas uniones, algo más de 17.000 correspondían a matrimonios entre un hombre español y una mujer extranjera, y cerca de 12.000 a bodas entre mujeres españolas y hombres extranjeros. Para el conjunto del período comprendido entres estos dos años (1996-2009), la proporción es similar: 151.190 hombres españoles se casaron con una mujer extranjera frente a las 103.440 mujeres españolas que hicieron lo propio con un hombre extranjero (Fuente: INE, elaboración propia) ${ }^{3}$.

Este «desequilibrio» entre hombres y mujeres españoles que eligen un cónyuge de nacionalidad extranjera alimentó una de nuestras hipótesis de partida, centrada en el hecho de que la notable transformación producida en el sistema de género en las últimas décadas, con cambios sociológicos de cierta consideración (incorporación de la mujer a los niveles superiores de formación y al mercado de trabajo y mayor capacidad de control y emancipación de su papel como reproductora), que han producido una mayor independencia material y sentimental de las mujeres españolas, estaría ocasionando la resistencia de algunos hombres, que, en desacuerdo con este nuevo y cada vez más generalizado modelo femenino, se habrían lanzado a buscar pareja en un mercado matrimonial distinto al del propio país, en el marco de lo que ha venido a denominarse en los últimos años «crisis de la masculinidad» ${ }^{4}$. El objetivo de tal búsqueda estaría claro: el hallazgo de mujeres con un perfil similar al de las mujeres españolas de hace unas décadas, ahora supuestamente abandonado. Esto es, mujeres que priorizarían la casa y la familia por encima de la profesión y el trabajo y aceptarían unas relaciones de género fundadas en un cierto grado de sumisión y dependencia al esposo. En este artículo no vamos a tomar en consideración las motivaciones de los hombres españoles para realizar una unión binacional, sino la de las mujeres no españolas que se unen a ellos. No obstante, vamos a

3. Si bien hay que señalar que no es hasta el año 1999 que los hombres toman la delantera a las mujeres españolas en uniones matrimoniales con un cónyuge extranjero.

4. Véase, con carácter general, MacInnes, 1998; Mac an Ghaill, 1996, y Seidler, 2006; y para el caso español, Gil Calvo, 1997, y Flaquer, 1999. 
señalar, muy sucintamente, que nuestros datos nos permiten afirmar, en relación con la hipótesis planteada, que existe, efectivamente, un perfil destacado de hombre español, generalmente divorciado y mayor de cuarenta años, que expresa este tipo de motivación. Véase, a título únicamente ilustrativo, cómo la articulan dos de nuestros informantes que responden a este perfil:

La mujer catalana [es] una mujer independiente, segura de sí misma, no necesitan al macho para casi nada, quiero decir que pueden hacer su vida perfectamente. Las de allí [Rusia], de alguna manera, quizá la palabra no es la correcta, pero aún tienen una cultura antigua de una pequeña devoción al macho. Entonces nosotros, yo, como soy un cobarde, y ya no me atrevo con las catalanas, porque es una lucha constante de si hacemos esto y demás, y yo de todo eso ya me cansé en mi tiempo y dije: «iBasta!». Entonces buscas una cosa, para tener una relación más fácil y que de alguna manera te traten un poco más así ¿no?*5. (Josep Maria, español, 56 años; casado con rusa, 25 años)

Y en principio pues sí, vi que las mujeres de allí... que su forma de ser coincide bastante con esa apreciación que uno tiene: cariñosas, sumisas... Y además tienen una combinación muy interesante porque no sólo son cariñosas, suelen ser apasionadas, y me reitero en la cuestión, y... bueno, complacientes, mujeres muy al gusto de un hombre. Además tienen interés en cuidar la casa, no les importa realizar las tareas del hogar en un momento determinado. De alguna manera, tienen una forma de ser... a mi gusto; encaja bien en mi circunstancia. Por ejemplo, Sol no está trabajando, bueno yo me puedo permitir que ella no trabaje, y, además consideramos que... no porque no quiera yo que trabaje, sino que consideramos que es lo mejor para el niño en los primeros años de su vida [...]. Porque la forma de ser que ellas tienen encaja muy bien en la que yo como hombre tengo*. (Jordi, español, 41 años; casado con venezolana, 37 años)

Con ser importante, no obstante, este perfil masculino no es el único. Debemos considerar asimismo la existencia de muchas parejas binacionales, con hombres españoles de edades generalmente más jóvenes que las del modelo citado, resultantes de los procesos de movilidad creciente que amplían las posibilidades de comunicación, también en el territorio amoroso, y alejadas por tanto de este tipo de motivaciones.

La literatura que recoge la investigación en este terreno y que se centra en las mujeres que migran para casarse, por su parte, presta atención a los principales itinerarios que recogen los flujos de cónyuges y parejas, así como también a la dirección y al sentido de los $\operatorname{mismos}^{6}$, pero describe también los

5. El asterisco, cuando acompañe a alguna cita, indica que la entrevista se realizó originalmente en catalán y que, por tanto, hemos traducido el texto.

6. Como los de Cahill (1990) y Cooke (1986) sobre esposas filipinas de maridos de diversos países; Suzuki (2003) y Parreñas (2010), centrado en matrimonios transnacionales entre filipinas y japoneses; Mainardi (2006), que analiza parejas de brasileñas y suizos, y Riaño (2003), de suizos y latinoamericanas; Chin (1994), ocupado en mujeres chinas casadas transnacionalmente; Cohen (1986), en tailandesas; Halualani (1995) y Robinson (1996), en asiáticas, y De Melo (2000), en brasileñas. 
diversos patrones de género vinculados a la movilidad marital en un contexto global (Constable, 1998, 2003; Thai, 2008), mostrando a mujeres y hombres que toman la iniciativa, que realizan elecciones y que devienen agentes activos, apuntando las motivaciones y razones para la salida, los nuevos patrones de movilidad de personas de las distintas clases sociales, los costes y beneficios de la salida o la permanencia en el país (Parreñas, 2010), los factores que intervienen en la elección de pareja (Jo-Pei et al., 2008), el papel de las nuevas tecnologías en estos procesos (Johnson, 2007; Johnson-Hanks, 2007) y la consideración de la noción de mercantilización asociada a este nuevo mercado sentimental global (Wang y Chang, 2002), así como las nociones y expresiones de amor, intimidad y sexualidad que tales relaciones entrañan (Nemoto, 2006; McFadden y Moore, 2001; Lyons y Ford, 2008), su incidencia en los roles identitarios (Ordóñez, 1997; Pipper y Roces, 2003), especialmente de género (Riaño y Baghdadi (2007), y su relación con procesos de divorcio e inestabilidad conyugal (Kalmijn, De Graaf y Janssen, 2005; Neyrand y M’Sili, 1997), además de la consideración de las parentalidades mixtas (Crippen y Brew, 2007) y los procesos, en fin, de comunicación y de negociación (inter)cultural (Delcroix y Guyaux, 1992).

En relación con España, tan sólo conocemos nuestro trabajo pionero (Roca, 2007; Roca et al., 2008), del que han ido derivándose ya algunas publicaciones (Martínez, 2007; Roca, 2009; Bodoque y Soronellas, 2010). En el ámbito más general de las denominadas "parejas mixtas o binacionales» — que puede incluir o no a las resultantes de migraciones amorosas-, deben citarse las aportaciones de Rodríguez (2004), a quien interesa principalmente el carácter intercultural y exogámico de las parejas mixtas; Bermúdez (2007), centrada en las parejas mixtas de la Comunidad Valenciana; Santacreu y Francés (2008) y Albert y Masanet (2008), ambas nucleadas en torno a la cuestión de la interculturalidad, y algunas de las ponencias del seminario organizado por el Centro de Estudios Andaluces, como las de Esteve (2009) y Steingress (2009).

\section{El amor como motivo}

El enfoque de género aplicado al estudio de los procesos migratorios ha puesto de relieve no sólo las singularidades de las experiencias migratorias femeninas, sino también el carácter complejo, cambiante y poliédrico de los proyectos migratorios. En las mujeres, como en los hombres, no hay una razón única para emigrar, pero es en la emigración femenina donde se hace particularmente visible la yuxtaposición de las motivaciones diversas que intervienen en la decisión migratoria. Las mujeres se van para mejorar, y en su deseo de mejora se condensan razones económicas, pero también razones que tienen que ver con su emancipación, con la toma de distancia respecto a relaciones conyugales y de género insatisfactorias $y$, también, con el amor. Nuestras informantes nos han hablado del amor como la gran razón de su particular migración. Se trata de mujeres que describen su proyecto migratorio desde los sentimientos y que, como veremos, en muchos sentidos no se sienten mujeres migrantes, incluso 
niegan serlo, puesto que el amor y la conyugalidad les dan argumentos para alejarse de las motivaciones económicas que tienden a asociarse con la migración, con lo cual legitiman su movilidad internacional por razones sentimentales. Tras el discurso émico del amor, se esconde la complejidad de la migración de unas mujeres que tienen, en la búsqueda de pareja en un país extranjero, una posibilidad, entre otras, de marchar en busca de nuevas oportunidades.

Entendemos, tomando a Bourdieu (1997), que estas mujeres construyen sus campos sociales (transnacionales) a partir de una combinación de capitales (cultural, económico, social y simbólico) que van siendo redefinidos a lo largo del proceso migratorio. Dicho capital tiene carácter multidimensional, en el sentido que debemos tomarlo como una combinación de recursos estrechamente vinculados $\mathrm{y}$, por tanto, no segregables, que las migrantes tienen a su disposición para jugar sus cartas en el espacio social. Las migraciones por amor nos ofrecen la posibilidad de comprender la dificultad de separar las capacidades económicas (materiales) de las sociales (capacidad de relación) o culturales (formación, origen) y, menos aún, de la posición, el prestigio o el reconocimiento social (capital simbólico). Las mujeres, como actores sociales y como agentes capaces de decidir sobre su destino, construyen y utilizan estratégicamente sus «capitales» para conseguir sus horizontes de reproducción social. Siguiendo de nuevo a Bourdieu, la migración es un recurso integrado en el habitus, entendido como disposición estratégica a seguir determinadas conductas, un recurso que las mujeres tienden a explicar y a legitimar mediante el argumento del enamoramiento, cuyo análisis nos descubre un horizonte migratorio singular y complejo.

Los relatos de nuestras informantes nos han acercado a esta complejidad. Uno de los factores migratorios es, sin duda, la existencia de un marcado sistema patriarcal que explica tanto las restricciones de la movilidad femenina como los impulsos a la emancipación (Gregorio, 1998; Pedone, 2008). Se ha analizado también cómo la segregación de los mercados de trabajo fomenta la ocupación de las mujeres en determinados sectores de mayor demanda en los países de destino (trabajo fabril, doméstico, atención a la dependencia y prostitución) y las alejan de las precarias oportunidades de desarrollo profesional de que disponen en sus países de origen. Las mujeres se han referido también a la experiencia estigmatizada en el ámbito doméstico, caracterizada por la existencia de unas arraigadas y desiguales relaciones de poder en las que tienden a ocupar posiciones subordinadas (Soriano, 2006) y, en concreto, la que ocupan respecto a los hombres de su país y de su mismo estrato social, además del extremo machismo local caracterizado por la posesividad, la agresividad, el distanciamiento afectivo, la falta de respeto o la infidelidad (Piscitelli, 2004). Otras nos hablan de motivos más sutiles para migrar, como son los estados del alma (Agustín, 2003), es decir, el deseo de cambiar, la aspiración de mejorar sus condiciones de vida y otros estados de frustración y angustia, ideales para constituirse en elementos que pueden favorecer la búsqueda de unas relaciones de género distintas vinculadas al ámbito amoroso y sentimental. Así, la migración es para las mujeres un contexto de oportunidad en el que deciden 
ser agentes de su propio destino (Agustín, 2003). Estas razones explican que busquen la forma de garantizar su movilidad y que una de las estrategias sea el encuentro de un compañero sentimental, o un marido, en el extranjero, atendiendo a criterios estereotipados según los cuales los hombres de determinados países, en este caso los españoles, son menos machistas, menos infieles, menos agresivos y menos posesivos.

El análisis de los datos nos ha permitido dar forma a una de las hipótesis que condujo nuestra investigación y es que uno de los motivos de las migrantes por amor, para casarse con un extranjero es emanciparse y conseguir mejorar las condiciones de vida que tienen en sus países de origen. Esta opción las expone a un contexto social potencialmente hostil y suspicaz en la valoración de los motivos de su migración, por lo que, ante la presión social, sienten la necesidad de reivindicar la naturaleza romántica de su llegada y, en algunos casos, de alejarse de los miembros de los colectivos migrantes convencionales. $\mathrm{Y}$ es que la mejora en las condiciones de vida va mucho más allá del incremento del nivel económico: se trata de la consecución de un determinado estilo de vida; de la capacidad de acceder a trabajos acordes a su formación académica y profesional; del acceso a redes de relaciones sociales; de sus posibilidades de ser independientes y autónomas; de la sensación y percepción de seguridad y bienestar; etc.

Entre la pluralidad de situaciones halladas en las entrevistas, destacamos las de aquellas mujeres que gozaban de niveles de bienestar económico que las satisfacían, que niegan haber tenido la emigración en su horizonte personal y cuentan que el matrimonio con un extranjero no se encontraba entre sus planes de futuro. Algunas, como Yadira, una mujer mexicana de 32 años, nos intentan explicar la ambivalencia de sus sentimientos y cómo le ha resultado angustioso, a la vez que esperanzador, salir al extranjero en pos de su pareja, siguiendo la llamada del amor:

Tenía miedo de dejar todo allá, todo lo que conocía, a mi familia, a todo, a todo. Tenía mucho miedo [...] no era tanto a dónde iba a llegar a vivir, sino el cambio y todo lo que dejaba. Yo allá prácticamente era autosuficiente, yo trabajaba, yo tenía mi coche, yo... me compraba lo que se me ocurría porque prácticamente trabajaba para mis gastos, vaya, para mí. Entonces el hecho de venir, no sé, como que me entró pánico. Como si me hubiera metido en un túnel y no veía por ningún lado y sentía que no podía hacer nada [...] y también me costaba mucho cortar con lo que ya estaba empezando a crear, como quien dice, estaba haciendo mi montañita y ipum! Lo dejé a medias y me vine aquí a construir otra.

Aún así, decidió marchar hacia España para vivir con su pareja. Abandonó, como otras mujeres latinoamericanas entrevistadas, su vida anterior y se encomendó a la aventura de la migración. La mayor parte de estas mujeres pertenecen a clases medias y han tenido acceso a estudios superiores, todas han conocido a sus parejas a través de chats especializados y nos describen situaciones de estabilidad y de bienestar familiar, personal y profesional en origen. 
Nos explicaron qué las había impulsado a emigrar y qué temores las retenían, nos contaron sobre las dudas previas a la toma de la decisión más arriesgada, la partida. Todas aludían a la ilusión del enamoramiento como la causa principal que las impulsaba a emigrar, pero, en el relato del proceso, entrevemos otros motivos para buscar una pareja en el extranjero: unos más velados, como es el miedo a la soltería (nos dice Sonia, peruana de 35 años, "que ya me veía que me quedaba soltera»), otros más explícitos, como el machismo de los hombres de su país y las pocas oportunidades de que disponen allí para llevar a cabo conjuntamente sus proyectos personales y profesionales.

La mayor parte de mujeres entrevistadas procedentes de países del Este, en unas circunstancias parecidas a las de las mujeres latinoamericanas, sí que prevén la migración por amor explícitamente como forma de salir de una situación personal precaria: con estudios universitarios e incluso varias carreras cursadas, con trabajos para los que estaban muy bien preparadas, se sienten insatisfechas ante la precariedad de los sueldos (por debajo de los 300 euros mensuales), que no les permiten asumir el estilo de vida que suponen a los países occidentales. También son mujeres, como Natalia, una mujer rusa de 25 años, pertenecientes a clases medias e incluso medias altas enfrentadas a una situación de desencaje entre los niveles profesionales de la población y las retribuciones, o, lo que es lo mismo, entre las expectativas formadas en una población que está preparada para acceder al atrayente estilo de vida occidental y la realidad de una situación económica que las aleja de ese modelo.

Entonces esto [emigrar] era una cosa increíble para mí porque yo ni lo pensaba. Yo nunca pensé... A ver, no es que miento pero sí que siempre sabía que no me quedaría en mi país, no sé, si me iría a la capital, pero algo grande, algo donde hay más posibilidades, más movimiento, no sé, más todo. Yo sabía que en mi pueblo, donde nací, no me podía estar toda mi vida. Ya lo veía. Sabía que había problemas económicos, que faltaba trabajo, bueno bien pagado. No tenía pareja y a los 21 años tampoco es normal [...] mi país creo que es el único país del mundo que ha sufrido tantas guerras, que ha sufrido tantas cosas... Todo eso como que hace bajar el desarrollo.

La salida del país es una de las estrategias utilizadas para encajar las expectativas y la realidad, y la migración conyugal entra dentro del catálogo de formas de conseguirlo. Algunas no expresan de una forma tan patente como otras la ilusión del enamoramiento y no aluden tanto al amor en la intencionalidad primaria de migrar, pero para todas esta situación de partida se da en un contexto favorable de tradición y de cultura migratoria que contribuye a afianzar la toma de decisiones. Y son ellas, en mucha mayor medida que los hombres, quienes deciden marcharse utilizando la vía matrimonial. Así nos lo explica Mayya, una mujer ucraniana de 26 años:

R: Allí se marchan todas cada hora, y mira que ya casi cerraban las fronteras e igual marchan todas... ¡Madre mía! Marchan todas donde sea, pero marchan: que sube todo, que las nóminas no suben [...] Las amigas todas han marchado, 
no queda ninguna, no vas a encontrar ni una, ni una, ni una: amigas mías, ni una.

P: La decisión de venir es muy valiente.

R: No, a mí no me ha parecido muy valiente, eh! No. Allá no tenía nada, no tenía trabajo, ni siquiera mi madre no podía darme estudios ni a mis hermanos*.

El matrimonio se convierte en una peculiar forma de conseguir salir del país y de alejarse de una situación personal insatisfactoria y precaria a diferentes niveles. Se trata, pues, de una migración diferenciada y muy penalizada socialmente en los países de llegada, donde el amor al que aluden estas mujeres es considerado como una suerte de «tapadera" para la migración. La consolidación, en nuestras sociedades occidentales, del ideal romántico del matrimonio por amor nos ha alejado de todo aquello que rezuma a interés en las uniones conyugales. El amor ha invisibilizado el carácter institucional del matrimonio, y sus fuertes implicaciones económicas, políticas y sociales, que existen, son prácticamente negadas, especialmente al principio de la relación. Desde nuestro punto de vista, las mujeres que deciden unirse sentimentalmente a un hombre extranjero son agentes activos que toman una decisión entre otras posibles, y el resultado de su elección, como el valor de su compromiso, no tiene por qué diferir de las elecciones y de los compromisos tomados en otras circunstancias y por parejas nacionales. Que la retórica romántica abomine de las dimensiones instrumentales del matrimonio y que hayamos incorporado a nuestro inconsciente la necesidad de negarlas, no las hace menos presentes y efectivas. De ahí que algunas de estas migrantes por amor no tengan reparos en admitir su deseo por mejorar sus condiciones de vida y la atracción que sienten por «una vida más fácil, más oportunidades, sin tantos constreñimientos materiales. Una vida más confortable y segura que el medio social europeo ofrece» (Aymée, cubana de 31 años) o «una vida más fácil, más oportunidades de trabajo, sin tantos desórdenes ni inseguridades» (Laura Sofía, venezolana de 32 años), aunque todas ellas confiesan hasta la saciedad que lo que verdaderamente las estimuló a la aventura migratoria fue el amor y el posterior establecimiento de una familia.

En síntesis, pues, apuntamos la necesidad de considerar una pluralidad de causas y motivos en las que hemos denominado «migraciones por amor». Debemos señalar, en este sentido, la existencia de una combinación de razones de tipo sentimental —el amor, el enamoramiento entre dos personas de países distintos facilitado por el incremento y el desarrollo de la movilidad, tanto física como virtual-, de carácter material - la expectativa de mejoras en las condiciones de vida y en el desarrollo profesional en el país de destino- y del ámbito de las relaciones de género - la agencia de las mujeres por superar relaciones de género de signo tradicional y patriarcal y de alcanzar relaciones de género más igualitarias. Es evidente que tal esquema, por una parte, adquiere combinaciones diferentes en función de variables fundamentales como la clase social, el nivel de formación, la etnia y el país o la región de procedencia de las mujeres, $y$, por otra parte, que debe situarse en un nivel de complejidad 
que permita, entre otras, incorporar las voces diferenciadas de las protagonistas directas del proceso migratorio y de diversos actores pertenecientes a las respectivas sociedades de origen y destino; la distancia entre las expectativas y las experiencias concretas y entre lo que se afirma, y el contexto en el que se afirma, y lo que otro tipo de datos indirectos permite corroborar; o la constatación, por ejemplo, en suma, que el Oeste, el Norte, no es simplemente el lugar de liberación, aunque pueda imaginarse como tal para muchas personas, sino que representa e implica, asimismo, la posibilidad de nuevas formas de poder, de nuevas opresiones y también de nuevas oportunidades.

\section{Amor y papeles: esposas y migrantes}

La celebración institucional de la unión no siempre tiene lugar y, cuando se realiza, no en todas las ocasiones se casan previamente a la salida del país. Generalmente, las parejas formadas por mujeres latinoamericanas y hombres españoles se casan antes de emigrar, ya sea por imperativos de salida, como en el caso de Cuba, ya sea como una forma de dar legitimidad a la relación, sobre todo a ella y a su familia. Si el matrimonio tiene lugar con posterioridad a la emigración de la futura esposa, se produce después de un cierto período de convivencia que la pareja se concede para asegurar la relación, un período que es prácticamente exigido por la familia del esposo, la más recelosa respecto a la sinceridad y al resultado final de esta «aventura conyugal». Sea como fuere, cuando las parejas deciden establecer definitivamente su convivencia en España, son las mujeres las que buscan recursos variados para poder salir de sus países respectivos. La forma mayoritaria es consiguiendo un visado de turista que, en principio, es un trámite relativamente fácil, no obstante, en algunos países, la demora o la denegación de los documentos necesarios para la obtención del visado ha propiciado el desarrollo de complicadas estrategias de abandono definitivo del país, teniendo en cuenta que los proyectos se planean como irreversibles. Por su originalidad, seleccionamos el caso de Tania, ucraniana de 25 años, que hace cuatro años aprovechó un viaje que se organizó desde su país hacia Eurodisney para quedar en París con su novio español, Josep Maria — de 56 años—, y llegar juntos a España:

Quedamos en París y ella vino en un viaje de estos organizados teóricamente a Eurodisney, bien, de estos viajes que al final el autobús se queda casi solo, ¿no? [...] Para venir a España directamente tenía problemas de visado [...] en cambio ellos compraron todo el autobús donde vinieron, compraron todos billetes de ida y vuelta para ir a Eurodisney [...] Con la excusa de ir a Eurodisney, conseguían el visado y entonces, a partir de Alemania, empezaba a desaparecer la gente. En el autobús había una comisaría política que lo primero que hacía era recoger los pasaportes de todos y ella los guardaba. $Y$ a medida que la gente se iba marchando, se iba escapando, ella les devolvía el pasaporte, pero les pedía pasta. Venían chicas y gente de todo tipo [...] Ella pagó y le devolvieron el pasaporte. Y yo fui a buscarla allá y estuvimos dos o tres días por París y vimos que había sintonía y, mira, desde entonces [...] Estuvimos unos días y después 
fuimos bajando poco a poco, por algún pueblecito de vacaciones. Entonces entramos en España y buscamos una fronterita. No pasamos por la Jonquera por si acaso*.

Si no se institucionaliza la relación, las mujeres, una vez finalizado el tiempo permitido de estancia en España, pasan a una situación de ilegalidad. Es posible que, al cabo de dos años de estancia, consigan el permiso de residencia por arraigo e incluso se puedan casar, con lo que obtendrían un permiso especial como familiar de comunitario que ofrece muchas más ventajas. No obstante, intentar conseguir cualquier tipo de documentación que las integre jurídica y legalmente significa darse de bruces con la categoría que se ha intentado evitar hasta el momento: la de inmigrante. Tanto para ellos como para ellas, es el momento de soportar largas colas en las instituciones de extranjería, de tener la sensación de que los trámites nunca llegarán a su fin y, lo que es más incómodo, de sentirse juzgado por iniciar un trámite tan sospechoso a ojos de la sociedad autóctona. Algunos, como Manel -español de 35 años—- conociendo el grado de sospecha, desconfianza y recelo que planea sobre estas parejas, se apresuran a autentificar sus relaciones, a reivindicar su validez frente a otras relaciones parecidas y frente a lo que, en los medios de comunicación, se identifica bajo la categoría de «matrimonios blancos» y a cerrar filas en torno a su caso como único, culpando de los prejuicios suscitados a quienes están en una situación parecida a la suya y no a la estructura que sustenta estos prejuicios:

[...] allí en el consulado español ha habido... con esto de las mujeres rusas... con esto ha habido mucho jaleo. Ha habido muchas mujeres rusas que han vivido situaciones muy complicadas y han buscado un escape fuera para irse de aquella miseria. Y han conocido un tío, se han valido de un tío para marcharse de allí y cuando han llegado aquí y han visto un poco el sol, pues «ahí te quedas» y ¿qué pasa? Que todas se han marchado con un visado turístico y no han vuelto. Claro, se van de cualquier manera [...] y se quedan... ilegales pero se quedan. Y todo eso ha aumentado el control*.

Para Manel, la forma de conseguir legalizar la estancia de su novia ucraniana fue tan ardua y complicada que, de alguna manera, considera que es una prueba más de amor superada. De sus palabras se desprende que la dificultad de autentificar su situación y la obligación legal de ser evaluado por las estructuras de gestión de los flujos migratorios convierte a su pareja, no sólo en una migrante convencional, sino que la sitúan bajo el estigma de la sospecha, una situación que les aleja de la normalidad pretendida en cualquier relación de pareja: «[...] lo más complicado... lo más complicado de esta relación, que yo pensaba “¡Madre de Dios dónde me he metido!”, es el tema de venir aquí, el aspecto legal. Ha sido... ha sido una locura. Yo lo pasé mal, lo pasé mal»*.

Otro de los métodos más utilizados por las mujeres entrevistadas para salir de su país es mediante un visado de estudios que permite estancias mucho más 
prolongadas que el de turista. Aún así, el proceso es lento y costoso, tal y como nos lo relata Simeó, español de 38 años:

Primero planteamos que ella viniera aquí durante tres meses y no se lo concedieron. Le hice una invitación y, a través de mi hermana, le hicimos una invitación particular. Y le preguntaron cómo conoció a mi hermana y ella le dijo que la conoció en un viaje a Egipto y que por Internet habían mantenido el contacto, y se lo denegaron. Así estuvimos desde octubre, tres meses y pico. Claro, hay papeles que para tenerlos se necesitan meses: un certificado de penales... Allí la burocracia va muy lenta, tarda un mes y medio y te lo han de expedir en Moscú... Está todo centralizado. Esto mes y medio. Certificado de estudios, traducidos al español, que eso también vale pasta, etc., etc. Entonces, bueno, tramitar el visado solo son unos quince días, esto es fácil, lo que se trata es conseguir los papeles para tramitarlo. Y se lo denegaron y lo volvió a presentar y se lo autorizaron. Vino como turista un mes y medio. Volví por Semana Santa y entonces ella vino en marzo y estuvo tres semanas. Entonces la relación empezó a funcionar..., hasta que al final consiguió el visado de estudios. Vino aquí a vivir en diciembre de 2006, un año y medio aproximadamente y vino para quedarse. El visado de estudios era por cinco meses pero nosotros le prorrogamos los estudios un año*.

En este tipo de procesos, las personas implicadas son generalmente los dos miembros de la pareja y en mucha menor medida, por no decir nunca, intervienen las cadenas familiares o de paisanaje con sus redes de apoyo correspondientes. Las mujeres migrantes por amor llegan a los países de destino con un proyecto migratorio especialmente individualizado, puesto que proyectan personalmente una migración que tiene como instrumento la formación de una familia o, simplemente, el establecimiento de una relación conyugal en destino. Existen también cadenas y redes, aunque en este contexto adoptan formas completamente distintas. Y es que, a pesar de que el carácter individual de la migración las deja fuera de las cadenas migratorias de tipo familiar (ni las inician, ni las continúan), sí que se detecta la existencia en destino de un tipo de redes que no son de apoyo, tal y como se manifiestan las que complementan a las cadenas migratorias comunes, cuya trama débil nos lleva a calificarlas como redes de emergencia. Se trata de contactos que se establecen desde origen con amigas, familiares lejanos, paisanos o algún antiguo compañero de universidad, que han hecho anteriormente el mismo camino, que se localizan en un área relativamente próxima al lugar de residencia de las migrantes por amor y a los que recurrirán, según nos explicaron, como recurso alternativo al posible fracaso del proyecto. Según Pascual (2007: 19), este tipo de redes ejercen el efecto de tranquilizar emocionalmente a las familias y a las mismas migrantes, reducen los riesgos que supone el cambio de contexto, de manera que el desplazamiento se torna mucho más simple. Las redes de emergencia son diferentes a las de apoyo, ya que, por su carácter de último recurso y por no proceder de una cadena migratoria tradicional, se las despoja de su potencialidad como capital social (del que las migrantes por amor se verán 
beneficiadas a través de la propia relación conyugal). Finalmente, las cadenas tradicionales de paisanaje o familiares, en el contexto de las migraciones por amor, son sustituidas por lo que, en otro lugar, hemos denominado «cadenas sentimentales» (Bodoque y Soronellas, 2010; Martínez, 2007):

Me lo presentó una amiga que conocía a Luis. Me presentó primero por foto y me ha dicho que es un buen hombre y ella sabía que yo estoy sin pareja, y que es un hombre atento, me ha dicho cosas positivas y yo tuve ganas de conocerlo.

Quienes han de salir de su país de origen, que, con mayor frecuencia, son las mujeres como Tatiana — rusa de 35 años—, tejen sus particulares cadenas y redes de relaciones de manera que una mujer puede ser creadora de una cadena sentimental a la que otras se unan realizando un recorrido similar. El inicio de una cadena se puede establecer a través de la divulgación de testimonios favorables que representen un estímulo para otras mujeres y otros hombres a hacer lo mismo (como Cisco, español de 32 años, y sus amigos): son vehículos para iniciar otras relaciones poniendo en contacto amigos y conocidos a través de la circulación de fotografías, presentaciones personales o simplemente hablando por teléfono sin, a veces, ni siquiera haberse visto nunca.

[...] había uno de los tres, que yo no le conocía, que ya tenía una historia con una chica cubana y se llamaban por teléfono. No había ido, pero una gente que había ido habían conocido una chica, muy buena persona, que quería conocer a alguien de fuera y tal y le dieron la dirección y el teléfono de éste. Hacía dos años que se llamaban y no se conocían. Y hablaban... solamente por teléfono, tenían alguna foto, se mandaban alguna carta...*.

\section{Irse sin mirar atrás}

Mientras que otros proyectos migratorios acostumbran a tener fecha de caducidad, las protagonistas de nuestra investigación dejan su entorno familiar y social con la intención de formar parte de un nuevo grupo familiar y de una nueva red de relaciones en destino. La falta de proyecto de retorno es un factor estructural para entender los campos sociales transnacionales (Suárez, 2008) que se constituyen en el contexto de las migraciones conyugales y para comprender el tipo de relaciones que estas mujeres establecen con el lugar de origen y con las redes familiares y sociales que allí dejaron.

Las migrantes llamadas «económicas» (una tipificación que simplifica la realidad y que no toma en consideración la migración como proyecto personal y como contexto de oportunidad también social) dejan muy a menudo a su familia en el país de origen, los hijos, el cónyuge especialmente, por lo que el envío de remesas es la práctica transnacional más relevante, a la par que paralelamente transmiten el afecto, la autoridad, su capacidad negociadora y todo lo que tiene que ver con el ejercicio de su rol familiar, es decir, llegan mirando atrás, hacia la parte de familia que quedó en la otra parte de su nuevo campo social (Bryceson y Vuorela, 2002; Parreñas, 2005; Parella, 
2007; Pedone, 2008; Sanz, 2009; Levitt, 2010). Por el contrario, las migrantes por amor llegan mirando hacia adelante, hacia la sociedad donde piensan forjar su destino. ¿Cómo se configura, entonces, el vivir transnacional de estas mujeres que emigran con un proyecto de familia? Sin perspectivas de retorno, los vínculos con el país de origen, con las familias y las redes sociales de los lugares de procedencia son frágiles (Bodoque y Soronellas, 2010). Después de una primera fase de noviazgo vivida en la transnacionalidad (Martínez, 2007), llegan, como Sonia, deseando iniciar la etapa presencial de la relación de pareja, de manera que sus energías emocionales y relacionales se vuelcan hacia el marido y su entorno social y familiar: el enamoramiento justifica la nueva situación:

Fue más que todo por él. O sea, porque me surgió... Creo que, como ya había sido decepcionada y me vino él y me llenó de tantas cosas... No fue ni por salir de mi país que es tan guapo, bueno aquí también, pero allá es mi mundo y mi vida y mis amigos, pero es una cosa que, como te digo, estuve en una nube y sentía cosas que no había sentido.

A la par, van descubriendo algunas reticencias y resistencias a la relación, provenientes de la red familiar y social del marido, que observa con cautela a la pareja y, especialmente, a una mujer extranjera a quien acusan abierta o veladamente de buscar en el matrimonio una forma de promoción social. La boda y la nacionalización actúan a favor del proceso de incorporación de la mujer extranjera en el entorno del marido y facilitan el distanciamiento de su condición de migrante, como desea Mayya, a la vez que la aleja real y simbólicamente de los entornos que dejó en origen.

R: En julio fuimos a mi país y el año que viene vendrá mi madre aquí.

P: :A vivir?

R: No sé. Yo no le he preguntado si quiere. Vendrá dos semanas.

Respecto a las remesas que eventualmente ellas pueden enviar a sus familias en origen, los maridos o parejas tienden a mostrar una actitud comprensiva ante tal necesidad, pero relativizan la intensidad de la misma e incluso pueden poner en duda ponerla en práctica. Ellos, como Simeó, enfatizan la individualidad de dos grupos familiares distintos, el de aquí y el de allí, y cada cual debe resolver de manera autónoma su estrategia de reproducción en función de sus propios contextos sociales, culturales y económicos:

Yo, por ejemplo, he tenido problemas con ella por el concepto de familia. Yo tengo muy asumido que mi familia son ella y la niña. Respeto que ella tiene a su madre, etc. Lo respeto, pero claro, que su familia... [...] Yo tuve problemas este verano porque se vendía la parcela contigua a su dacha (la típica casa de campo rusa) y la querían comprar, correcto, pero, ja mí qué me cuentas? Ella tenía muy claro que tenía que colaborar y que son su familia. Sí, ya lo sé que es tu madre, pero... no, no, no*. 
La llegada de los hijos tiene un alto valor simbólico para las mujeres migrantes por amor, dado que consolidan la relación con su pareja, afianzan su posición, mitigan las sospechas y las dudas que la relación pudiera haber despertado en el entorno familiar del marido, cimentan el proyecto de familia en destino, legitiman la relación, acaban de dar sentido a la búsqueda iniciada tiempo atrás y apartan algunos de los fantasmas del estigma del matrimonio por interés. Existen también, entre las migrantes por amor, las que responden al modelo de familia deslocalizada de madre en destino que ejerce la maternidad transnacional enviando remesas y manteniendo contacto frecuente. Justo cuando el noviazgo transnacional ha concluido, se abre otro proceso para reconstruir y rediseñar, desde la distancia, las relaciones de la mujer y su pareja con los hijos de ella. El flujo de sentimientos, afectos, cuidados y bienes que se estableció entre el país de origen y el de destino durante el periodo de noviazgo, y que permitió construir la relación conyugal, debe continuar para mantener la relación con los hijos y los lazos afectivos, resignificados, hasta el momento de su reagrupación.

La presencia de hijos comunes de la nueva pareja acostumbra a dar paso también a una fase de mayor negociación en las relaciones de género. La estabilización que contribuye a alcanzar la llegada de los hijos permite plantear cuestiones como la distribución de las tareas domésticas y de cuidado y, más adelante también, el que se constituye en muchas ocasiones como el principal motivo de desencuentro y, a veces, de finalización de la relación: la incorporación de la esposa al mercado laboral.

\section{Proyecto individual y de familia en destino: replantear la reagrupación}

De su discurso se desprende que las mujeres tienden a priorizar su rol de esposas en destino frente al rol de madres, cuando lo son, como una forma de afianzar la relación antes de incorporar a los hijos propios en el nuevo proyecto familiar. Una primera etapa de conyugalidad estricta es valorada como positiva para asegurar que la llegada de los hijos no entorpezca la relación de pareja y el futuro proyecto de familia en destino. Así es como se lo plantearon Priscila y su marido respecto al hijo de ella, que estuvo en casa de la abuela los dos primeros años de la relación de pareja.

La relación con la familia de orientación que quedó en origen, padres, abuelos, hermanos, es constante, aunque va debilitándose con el pasar del tiempo. A pesar de mantener relaciones con sus familiares, especialmente con las madres y los padres, las mujeres miden la intensidad y la frecuencia de la relación en un intento de no herir las sensibilidades de la pareja y de su entorno familiar. Una excesiva relación de las mujeres con el entorno dejado en el país de origen es percibida como un obstáculo a su integración en la sociedad de destino. Por esta razón, mujeres como Tania no se manifiestan partidarias de traer a sus padres, un argumento que refuerzan los maridos mientras, para justificar su oposición a la reagrupación, verbalizan la necesidad de enviarles algún tipo de ayuda económica, como una forma 
de tranquilizarlos y de restar intensidad al sentimiento de obligación de las mujeres para con sus progenitores.

Ella: Es complicado. Es que ellos son mayores, no podrán... Realmente ¿qué voy a hacer con ellos aquí?

Él: Bueno, algo se habló [...] Los padres ya son mayores, venir aquí, mantener otra familia... Evidentemente, primero somos nosotros, antes que mantener más familia. A cada uno le ha tocado lo que le ha tocado! [...] Bueno, lo que se intenta es mejorarles un poco las condiciones de vida, ayudarles un poco, que es mejor que traerlos aquí, porque se volverían a los dos meses. Ella algo les va enviando*.

Las mujeres entrevistadas mantienen una relación más intensa con sus madres que con sus padres, un comportamiento que nos recuerda que estamos ante mujeres que, en su mayoría, proceden de entornos familiares fundamentados en estructuras patriarcales con relaciones de género asimétricas, donde ellas ocupan una posición subordinada con respecto a sus hombres, sean éstos maridos, padres o hermanos. Aunque huyen de esa situación, algunas como Yadira manifiestan también que sus madres han sido cómplices de la migración por amor, en especial en el contexto latinoamericano, donde éstas son las garantes de la familia:

[...] ya no vivíamos con mi papá en México. Mis padres están divorciados y bueno, pues mi mamá es la que tenía la última palabra, porque si mi mamá también me hubiera dicho «no» [que no se casara], yo estoy segura de que, aunque yo hubiera querido casarme, no me hubiera casado con él. [...] Yo platiqué con mi mamá y le pregunté y mi mamá lo que me dijo fue: «Yo no te puedo decir no te cases ni cásate porque si te va mal, es algo que fue tu decisión. Y debes considerar que en esta casa vas a tener siempre las puertas abiertas por si quieres regresar».

Tras la migración, la relación con la madre se torna vínculo transnacional. Los viajes, las llamadas y las conexiones mediante Internet facilitan la continuidad de la relación en un contexto que se asemeja cotidiano y que permite casi olvidarse de la enorme distancia, a veces transoceánica, que separa a las madres de sus hijas. Las parejas de las mujeres, tal como nos lo explica Simeó con respecto a su esposa, no ponen ningún impedimento a la conexión telefónica o cibernáutica entre ellas y sus familias en el lugar de origen, al contrario, facilitan los medios técnicos necesarios para que los contactos se produzcan a placer:

[Ella habla con sus padres] por teléfono. Los llama una vez por semana, durante el fin de semana, normalmente. No tenemos teléfono fijo, aún. Vamos con el móvil, compramos una tarjeta con la que podemos llamar por el móvil. Marcando un código de la tarjeta, es como si se tratara de una llamada nacional. Ahora quiero poner Internet y quiero poner una camára web para que se puedan ver con su madre. 
Las visitas acostumbran a producirse desde aquí hacia allá y pocas veces al contrario. Es frecuente que se realicen con una periodicidad anual, por vacaciones, aunque a menudo los viajes son más espaciados debido al elevado coste de éstos. En algunas ocasiones, cuando los recursos de la pareja lo permiten, los viajes pueden ser más habituales («Él se cuida de que vaya porque se lo prometió a mi mamá», comenta Yadira). Es frecuente que las mujeres alarguen más el tiempo de estancia en su país de origen e incluso que realicen alguno de los viajes solas, sin la pareja. De este modo, ellos dan a sus esposas más libertad de relación con las familias de origen, se desprende de su discurso la voluntad de dejarles espacio suficiente para que sacien la sed de amor materno, para que mitiguen el sentimiento de añoranza que acumulan en el tiempo de separación. La añoranza, el luto migratorio por los paisajes familiares y sociales dejados en el lugar de origen está muy presente en estas mujeres, como en el resto del colectivo de personas que han emigrado de sus países. Por ello, es frecuente también que las mujeres tiendan a construir su propio mosaico social en destino a partir de otras mujeres a quienes pueden considerar «sus iguales»: las que comparten con ellas la condición de ser esposas o parejas de hombres españoles. En este sentido, el comportamiento de estas migrantes no dista demasiado del modo de actuar del resto del colectivo que tiende a construir entornos sociales propios a partir de personas iguales, frecuentemente familiares y conocidos en origen o, en su falta, con personas buscadas en destino entre sus semejantes. Algunas manifiestan tener algún tipo de relación con otros miembros de su colectivo nacional o con otras mujeres extranjeras casadas con españoles, aunque también encontramos reticencias de algunos maridos o parejas hacia el establecimiento de tales relaciones y, a menudo, una necesidad de controlar la intensidad de éstas. En algunos casos, las mujeres manifiestan abiertamente este control, en otros, describen la vigilancia a que son sometidas sus amigas y se manifiestan críticas al respecto. Los maridos se muestran indolentes sobre este tema, apoyan sin entusiasmo las relaciones, pero dan muestras de preferir que sus mujeres se integren en su red social, lo cual, por otra parte, no siempre resulta fácil. Y es que cuando las mujeres se encuentran con otros miembros del propio colectivo nacional o de otros grupos extranjeros, visibilizan su condición migrante, una condición que ellas mismas y, especialmente, sus maridos prefieren negar.

\section{En síntesis. Una migración negada y dependiente}

Estamos ante un tipo de migración femenina singular, vehiculada a través de una relación conyugal y legitimada mediante el ideal del amor romántico. Las mujeres migrantes por amor emigran solas, sin apenas cadena migratoria y sin apenas red de apoyo personal, parental o nacional, en destino. Múltiples negaciones son asociadas a este tipo de migración: vienen como novias esposas y mantienen unos vínculos con el país de origen que, a causa de la inexistencia de un proyecto de retorno, a menudo se van debilitando, incluso negando. Es frecuente que tomen distancia respecto al colectivo de su misma nacionalidad, bien como una forma de afirmar la diferencia — una 
suerte de negación de su propia condición de emigrantes—, bien porque a sus parejas no les parece conveniente o se sienten incómodas con este tipo de relación. Este nivel de negación a menudo contribuye a generar, entre las esposas migrantes por amor, una actitud de rechazo hacia su propia cultura de origen en términos muy parecidos a los de una auténtica conversión y en línea con la incorporación, por parte de la persona estigmatizada, del punto de vista de los «normales» que nos describe Goffman (1986), y, la última modalidad de negación, se trata de mujeres que, especialmente al inicio de su llegada, pueden ser (re)negadas por la red familiar y social de sus parejas, que las miran con recelo y suspicacia.

La mujeres migrantes por amor se singularizan también por responder a un tipo de incorporación a la sociedad de llegada que hemos calificado de dependiente (Bodoque y Soronellas, 2010). En primer lugar, estas mujeres llegan al país de destino en lo que parece una situación de ventaja en relación con las inmigradas laborales. Vienen a España sin la necesidad de utilizar cadena migratoria alguna, llegan con un proyecto de relación conyugal que les asegura que serán bien recibidas, acogidas, por su pareja y que les garantiza también el acceso a la vivienda y a los recursos básicos. Las características de su particular situación de primera acogida las sitúa en una posición de privilegio respecto a otros migrantes y contribuye a afianzar su negación de la situación migratoria. La primera incorporación no las hace sentirse migrantes, sino todo lo contrario, se sienten personas queridas que vienen porque alguien de la sociedad de destino ha deseado su llegada. Ellas mismas reiteran su visión de que inmigrantes son los que llegan obligados por las circunstancias, sin ser reclamados y, en consecuencia, son, o pueden ser, mal recibidos en la sociedad de inmigración. Sentirse deseadas en destino, queridas por sus parejas, las aleja del patrón migratorio y ocultan las dificultades, y los miedos, relacionados con la incorporación en la sociedad, en la comunidad, en el grupo social y en el entorno familiar de la pareja.

Las mujeres inmigradas por amor dejan en manos de sus parejas la responsabilidad de su incorporación y acomodo en la sociedad "de acogida». No es habitual que se preocupen de introducirse en redes de relaciones de compatriotas o de establecer contactos con otras personas desplazadas, por tres razones: en primer lugar, por el protagonismo que adquiere la pareja y su entorno social; en segundo lugar, porque tienen resuelta la situación económica mediante la pareja como proveedora de recursos, y, en tercer lugar, porque prefieren mantenerse alejadas de los colectivos migrantes, de sus estigmas. De este modo va constituyéndose un proceso de incorporación a la sociedad de acogida que calificamos de "dependiente», porque está capitalizado por el compañero sentimental, sus recursos y su propio entorno social. De esta forma las mujeres consiguen, nada más llegar al país de destino, los tres niveles de incorporación más difíciles para los migrantes: la jurídica, tener «los papeles», siempre que llegue a materializarse el matrimonio; la social, tener una red de parientes y amigos en destino, y la económica, disponer de capacidad de consumo. No obstante, se trata de una incorporación que convierte a la mujer en dependiente de su pareja y de su relación con ésta. La mujer llega para encajar 
en la posición social, económica y conyugal que su compañero ha diseñado para ella y para sí mismo. En otro momento y lugar nos ocuparemos de cómo las parejas mixtas negocian la continuidad de la relación y de cómo flexibilizan y transforman los términos de la dependencia referida.

\section{Referencias bibliográficas}

Agustín, Laura M. (2003). «Olvidar la victimización: Los migrantes como protagonistas». Développement, 46 (3), 30-36.

Albert, Ma Carmen y MASANET, Erika (2008). «Los matrimonios mixtos en España ¿Espacios de construcción intercultural?». Revista Obets, 1, 45-71.

BAUER, Thomas y McKercher, Bob (orgs.) (2003). Sex and Tourism: Journeys of Romance, Love and Lust. Nueva York: Haworth Press.

Bermúdez, Elba María (2007). Historias de unión y de amor en parejas mixtas que residen en la Comunidad Valenciana: Relatos desde la masculinidad y la feminidad. Valencia: CeiMigra, Bancaja.

BESSA, Fernando y SACRAMENTO, Octavio (2006). «A ilusâo da conquista: Sexo, amor e interesse entre gringos e garotas em Natal (Brasil)». Corpos, Dinheiro e Afectos, III Congreso da Associaciâo Portuguesa de Antropologia.

Bodoque, Yolanda y SORONEllas, Montserrat (2010). «Parejas en el espacio transnacional: Los proyectos de mujeres que emigran por motivos conyugales». Migraciones Internacionales, 5 (3), 143-174.

BouRDIEU, Pierre (1997). Razones prácticas: Sobre la teoría de la acción. Barcelona: Anagrama.

BRENNAN, Denise (2004). What's Love Got to Do with It?: Transnational Desires and Sex Tourism in the Dominican Republic. Durham: Duke University Press.

BRYCESON, Deborah y VuORELA, Ulla (2002). The transnational Family: New European frontiers and global networks. Oxford: Berg.

CAHILL, Desmond (1990). Intermarriages in International Contexts: A Study of Filipina Women Married to Australian, Japanese, and Swiss Men. Quezon City: Scalabrini Research Center.

Chin, Ko-Lin (1994). «Out-of-Town Brides: International Marriage and Wife Abuse among Chinese Immigrants». Journal of Comparative Family Studies, 25 (1), 53-71.

Clift, Stephen y CARTER, Simon (orgs.) (2000). Tourism and Sex: Culture, Commerce and Coercion. Londres: Pinter.

CoHEn, Erik (1986). «Lovelorn Farangs: The Correspondence between Foreign Men and Thai Girls». Anthropological Quarterly, 59 (3), 115-128.

Constable, Nicole (ed.) (1998). Cross-Border Marriages: Gender and Mobility in Transnational Asia. Filadelfia: Pennsylvania University Press.

CONSTABLE, Nicole (2003). Romance on a Global Stage. Berkeley: University of California Press.

CoOKe, Fadzilah M. (1986). Australian-Filipino Marriages in the 1980s. Queensland: Griffith University Press.

CRIPPEN, Cheryl y BREW, Leah (2007). «Intercultural parenting and the transcultural family: a literature review». The Family Journal, Counseling and Therapy for couples and family, 15 (2), 107-115.

Delcroix, Catherine y GuYAuX, Anne (1992). Double mixte: La rencontre de deux cultures dans le mariage. París: L'Harmattan. 
EsTEVE, Albert (2009). «Las parejas mixtas en España: crecimiento, singularidades demográficas y pautas diferenciales de origen». En: Parejas binacionales en la sociedad avanzada: realidades y tendencias en la hibridación transcultural [en línea]. Centro de Estudios Andaluces. <http://www.centrodeestudiosandaluces.es/datos/ factoriaideas/PN04_09.pdf>.

FLAQUER, Lluís (1999). La estrella menguante del padre. Barcelona: Ariel.

Gil Calvo, Enrique (1997). El nuevo sexo débil. Madrid: Temas de Hoy.

GofFMAN, Irving (1986). Estigma: La identidad deteriorada. Buenos Aires: Amorrortu.

Gregorio, Carmen (1998). Migración femenina: Su impacto en las relaciones de género. Madrid: Narcea.

Halualani, Rona T. (1995). «The Intersecting Hegemonic Discourses of an Asian Mail-Order Bride Catalog: Pilipina "Oriental Butterfly" Dolls for Sale». Women's Studies in Communication, 118 (1), 45-64.

HARris, John R. y TODARO, Michael P. (1970). «Migration, unemployment and development: a two-sector analysis». Economic Review, 60, 126-142.

Hondagneu-Sotelo, P. (1997). «I am Here, but I am There: The meanings of Latina Transnational Moterhood». Gender and Society, 11 (5), 548-565.

Jo-Pei, Tan; BAHARUdDIN, Rozumah; JUHARI, Rumaya y KraUSS, Erik (2008). «Sociodemographic characteristics of intercultural marriage: a study of a multi-ethnic community in Malasya». European Journal of Social Sciences, 5 (4), 30-44.

JOHnSON, Erika (2007). Dreaming of a Mail Order Husband: Russian-American Internet Romance. Durham: Duke University Press.

JOHNSON-HANKS, Jennifer (2007). "Women on the market: marriage, consumption, and the Internet in urban Cameroon». American Ethnologist, 34, 642-58.

Kalmijn, Matthijs; De GraAf, Paul; JANSSEN, Jacques (2005). "Intermarriage ant the risk of divorce in the Netherlands: the effects of differences in religion and in nationality, 1974-94». Population Studies, 59 (1), 71-85.

KING, Russell (2002). "Towards a New Map of European Migration». International Journal of Population Geography, 8, 89-106.

LeVITT, Peggy (2010). «Los desafíos del vivir familiar transnacional». En: GRUPO INTERDISCIPLINARIO DE INVESTIGADOR@S MigRANTES (coord.). Familias, niños, niñas y jóvenes migrantes: Rompiendo estereotipos. Madrid: Iepala.

LEVITT, Peggy y GLICK SCHILlER, Nina (2004). «Perspectivas internacionales sobre migración: conceptualizar la simultaneidad». Migración y desarrollo, segundo trimestre, 60-91.

LYONS, Leonore y FORD, Michele (2008). «Love, sex, and the spaces in-between: kepri wives and their cross-border husbands». Citizenship Studies, 12 (1), 55-72.

MaC AN GHAIll, Máirtín (ed.) (1996). Understanding Masculinities: Social Relations and Cultural Arenas. Buckingham, Filadelfia: Open University Press.

MacINESS, John (1998). The End of Masculinity: The confusion of sexual, genesis and sexual difference in modern society. Buckingham, Filadelfia: Open University Press.

MaInARDI, Giuditta (2006). Miroirs migratoires: Entre le Brésil et la Suisse: vécus de femmes brésiliennes. Bern: Peter Lang.

MARTíneZ, Lídia (2007). «Se busca esposa eslava/latina: El discurso de las agencias matrimoniales especializadas en mujeres del Este y de América Latina». En: $V$ Congreso sobre la Inmigración en España: Migraciones y desarrollo humano [en línea]. Valencia. <http://www.adeit.uv.es/inmigracion2007/index.php>.

MCFADDEN, John y MOORE, James L. (2001). «Intercultural marriage and intimacy: beyond the continental divide». International Journal for the Advancement of Counselling, 23, 261-268. 
Melo, Renata de (2000). «Vivendo um Conto de Fadas: O imaginário de gênero entre cariocas e estrangeiros». En: Goldenberg, Miriam (org.). Os Novos Desejos. Rio de Janeiro: Record.

Nemoto, Kumiko (2006). «Intimacy, desire and the construction of self in relationships between Asian American women and white American men». Journal of Asian Studies, 9 (1), 27-54.

Neyrand, Gérard y M’sili, Marine (1997). «Les couples mixtes dans la France contemporaine: Mariage, acquisition de la nationalité française et divorce». Population, 3, 571-605.

Ordóñez, Raquel Z. (1997). «Mail-Order Brides: An Emerging Community». En: Root, M.P (ed). Filipino Americans: Transformation and Identity. Thousand Oaks: Sage Publications.

Oso, Laura (1998). La migración hacia España de mujeres jefas del hogar. Madrid: Instituto de la Mujer.

- (2007). «Migración, género y hogares transnacionales». En: V Congreso sobre la Inmigración en España: Migraciones y Desarrollo Humano [en línea]. <http://www. adeit.uv.es/inmigracion2007/index.php>.

Parella, Sonia (2007). «Los vínculos afectivos de cuidado en las familias transnacionales». Migraciones Internacionales, 4 (2), 151-188.

PARRENAAS, Rhacel Salazar (2005). Children of Global Migration: Transnational Families and Gendered Woes. Stanford, CA: Stanford University Press.

- (2010) «Hacer el amor por un visado: la ciudadanía sexual de las inmigrantes filipinas en Japón». En: Familias en la migración: Emociones, solidaridades y obligaciones en el espacio transnacional. Barcelona: Icaria.

PAsCuAL, Ángels (dir.) (2007). Redes sociales de apoyo: La inserción de la población extranjera. Bilbao: Fundación BBVA.

Pedone, Claudia (2008). «Maridos aventureros vs. madres que abandonan: Reconstrucción de las relaciones familiares a partir de la migración ecuatoriana». Revista Interdisciplinar de Mobilidade Humana, XVI (30), 45-64.

Pettman, Jan Jindy (1997). «Body Politics. International Sex Tourism». Third World Quarterly, 18 (1), 93-108.

PIPER, Nicola y Roces, Mina (eds.) (2003). Wife or Worker? Asian Women and Migration. Nueva York: Rowman \& Littlefield.

Piscitelli, Adriana (2004). «El tráfico del deseo: Interseccionalidades no marco do turismo sexual no Nordeste do Brasil». Quaderns de l'Institut Català d'Antropologia, 4, 1-16.

PORTES, Alejandro (2005). "Convergencias teóricas y evidencias empíricas en el estudio del transnacionalismo de los inmigrantes». Migración y Desarrollo, primer trimestre, 2-18.

RiAÑO, Yvonne (2003). «Migration of Skilled Latin American Women to Switzerland and Their Struggle for Integration». En: Mutuso, Yamada (ed.). Latin American Emigration: Interregional Comparison among North America, Europe and Japan. JCAS Symposium Series 19, Osaka: JCAS, National Museum of Ethnology.

RIAÑO, Yvonne y BAGHDADI, Nadia (2007). "Je pensais que je pourrais avoir une relation plus égalitaire avec un Européen": Le rôle du genre et de l'imaginaire géographique dans la migration des femmes». Nouvelles Questions Féministes, 26 (1), 38-53.

Robinson, Kathryn (1996). "Of Mail-Order Brides and "Boys Own” Tales: Representations of Asian-Australian Marriages». Feminist Review, 52, 53-68.

RocA, Jordi (2007). «Migrantes por amor: La búsqueda y formación de parejas transnacionales». Aibr. Revista de Antropología Iberoamericana, 3 (2), 430-458. 
RocA, Jordi (2009). «Migraciones amorosas. Migraciones (re)negadas». Revista Migraciones, 25, 89-124.

RocA, Jordi et al. (2008). Amor importado, migrantes por amor: La constitución de parejas entre españoles y mujeres de América Latina y de Europa del Este en el marco de la transformación actual del sistema de género en España [en línea]. <http://www. inmujer.migualdad.es/mujer/mujeres/estud_inves/766.pdf>.

RodríguEZ, Dan (2004). Inmigración y mestizaje, hoy: La formación de matrimonios mixtos en familias transnacionales de población africana en Cataluña. Bellaterra: Publicacions de la UAB.

RothenBERG, John (1977). International Migration: A comparative perspective. Nueva York: Academic Press.

SANTACReU, Oscar y FranCÉs Francisco (2008). «Parejas mixtas de europeos en España: Integración, satisfacción y expectativas de futuro». Revista Obets, 1 [en línea]. <http:// www.iudesp.ua.es/va/publicaciones/revista/OBETSnumero1.pdf\#page $=46>$.

SANZ, Jesús (2009). Entre "cumplir» y «hacer cosas»: Estrategias económicas y simbolismo en el uso de las remesas de los inmigrantes ecuatorianos a España. Tesis doctoral disponible en: <http://www.tesisenxarxa.net/TESIS_URV/AVAILABLE/TDX1014109-140850//Sanz.pdf>.

SCHOLES, Robert (1999). "The Mail Order Bride Industry and Its Impact on Immigration». International Matchmaking Organizations: A Report to Congress [en línea]. <http://www.ins.usdoj.gov/graphics/aboutins/repsstudies.Mobrept_full.pdf>.

SEIDLER, Víctor J. (2006). Masculinidades: Culturas globales y vidas intimas. Barcelona: Montesinos.

Simmons, Lisa Anne (1999). «Mail Order Brides: The Legal Framework and Possibilities for Change». En: KelsOn, G.A. y DELAET, D. (eds.). Gender and Immigration. Nueva York: New York University Press.

SORIANO, Rosa M. (2006). Voces de mujeres desde la inmigración: Una comparativa entre el asentamiento de marroquies en España y mexicanas en EE.UU. The Center for Comparative Immigration Studies, San Diego: University of California.

STEINGRESS, Gerhard (2009). «Parejas binacionales en Andalucía: datos estadísticos y reflexiones micro-sociológicas de hibridación transcultural en las sociedades avanzadas». En: Parejas binacionales en la sociedad avanzada: realidades y tendencias en la hibridación transcultural [en línea]. Centro de Estudios Andaluces. <http://www. centrodeestudiosandaluces.es/datos/factoriaideas/PN04_09.pdf>.

SUÁREZ, Liliana (2008). "Lo transnacional y su aplicación a los estudios migratorios: Algunas consideraciones epistemológicas». En: SANTAMARía, Enrique (coord.). Retos epistemológicos de las migraciones transnacionales. Barcelona: Anthropos.

SuZUKI, Nobue (2003). Battlefields of Affection: Gender, Global Desires and the Politics of Intimacy in Filpina-Japanese Transnational Marriages. Manoa: Ph. D. Dissertation, Department of Anthropology, University of Hawaii.

THAI, Hung C. (2008). For Better or Worse: Vietnamese International Marriage in the New Global Economy. New Brusnwick: Rutgers University Press.

TruOng, Thanh-Dam (1990). Sex, Money and Morality. Londres: Zed Books.

WANG, Hong-Zen y CHANG, Shu-Ming (2002). "The commodification of international marriages: cross-border marriage business between Taiwan and Viet Nam». International Migrations, 40, 93-116.

ZolberG, Aristide R. (1983). "The Next Waves: Migration Theory for a Changing World». En: CoHEN, R. (ed.). Theories of Migration. Cheltenham: Edward Elgar Publishing. 
International Journal of Organizations
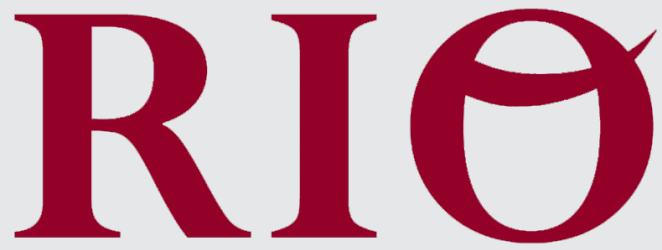

Revista Internacional de Organizaciones

Relaciones laborales y gestión de los recursos humanos en administraciones públicas

2

Negocios étnicos en España y Portugal

3

Pobreza, exclusión social y género

4

Revisifing Multinational corporations in the Twenty First Cenfury

5

Cuestiones sobre las organizaciones

6

Organización, lengua y migraciones

7

Sociología económica

RIO, Revista Internacional de Organizaciones, es una publicación del Servicio de Publicaciones y del grupo de investigación Análisis Social y Organizativo de la Universidad Rovira i Virgili, fundada el año 2008. El objetivo fundacional de la revista es servir a la comunidad científica y a la sociedad en general como medio de difusión de ideas y de investigaciones desde el campo de la sociología y de otras ciencias sociales afines. La revista RIO publica artículos, notas de investigación y recensiones de libros. 